\title{
Humean metaphysics versus a metaphysics of powers
}

\author{
Michael Esfeld \\ University of Lausanne, Department of Philosophy \\ CH-1015 Lausanne, Switzerland \\ Michael-Andreas.Esfeld@unil.ch
}

(in Gerhard Ernst \& Andreas Hüttemann (eds.): Time, chance and reduction. Philosophical aspects of statistical mechanics, Cambridge: Cambridge University Press 2010, chapter 7, pp. 119-135)

\begin{abstract}
The paper considers the opposition between Humean metaphysics and the metaphysics of powers, focusing on laws, probabilities and causation. It argues that within Humean metaphysics, everything is a matter of contingency. Consequently, there is no deep metaphysical difference between a deterministic world and a world in which only probabilistic laws hold. This position is contrasted with the foundations of probabilities according to the metaphysics of powers, in particular the view that traces probabilities back to propensities. The paper then goes into arguments for these positions, recalling first the central argument against Humean metaphysics, and then claiming that, contrary to a widespread belief, the metaphysics of powers is compatible with physics and is able to provide for an ontology that does justice to both physics and the special sciences.
\end{abstract}

\subsection{Humean metaphysics}

Whereas the philosophy of science was dominated in the second half of the twentieth century by epistemological issues raised in the context of logical empiricism and its critics, the project of a metaphysics of nature (metaphysics of science) has been rehabilitated recently. One can broadly distinguish three positions within that project: a Humean metaphysics that is close to empiricism (e.g. David Lewis, Barry Loewer and Helen Beebee), a metaphysics of universals (e.g. David Armstrong) and a metaphysics of powers (e.g. Sydney Shoemaker, Alexander Bird, Stephen Mumford as well as Charles Martin and John Heil). This paper is about the opposition between the first and the third of these positions. I shall first outline the Humean view on properties, laws, causation, and probabilities and point out how on the one hand this view is parsimonious, whereas on the other hand it provokes the objection that it is deficient (this section). I shall explain how the metaphysics of powers seeks to remedy these deficiencies and consider its view of probabilities (section 2). The paper then recalls the standard argument against the conception of properties in Humean metaphysics, goes into arguments from physics and finally maintains that the metaphysics of powers, in contrast to Humean metaphysics, is able to do justice to both the ontological commitments of physics and of the special sciences (section 3).

Humean metaphysics gets its name from the denial of the view that there are necessary connections between distinct entities in the world. Its most prominent formulation in contemporary philosophy is David Lewis' thesis of Humean supervenience: 
It is the doctrine that all there is to the world is a vast mosaic of local matters of particular fact, just one little thing and then another. (...) We have geometry: a system of external relations of spatio-temporal distance between points. Maybe points of spacetime itself, maybe point-sized bits of matter or aether or fields, maybe both. And at those points we 120 have local qualities: perfectly natural intrinsic properties which need nothing bigger than a point at which to be instantiated. For short: we have an arrangement of qualities. And that is all. There is no difference without difference in the arrangement of qualities. All else supervenes on that. (Lewis 1986, ix-x)

I shall take Lewis' statement to be characteristic of the position known today as Humean metaphysics. I shall not consider the relationship between that statement and the writings of David Hume. Humean metaphysics thus presupposes two things as primitive:

- the network of spatio-temporal relations between points of space-time. This is what unifies the world.

- the distribution of fundamental physical properties over the whole of space-time. Fundamental physical properties are all and only those physical properties that can occur at a point of space-time. Position, velocity, energy-mass, charge, spin count among the candidates for such properties. According to Lewis, these are natural, intrinsic and categorical properties.

Lewis' Humean metaphysics does not presuppose anything else as primitive. The description of everything else that there is in the world is to be derived from the description of the distribution of the intrinsic and categorical, fundamental physical properties over the whole of space-time. Everything else that there is in the world is a feature of that distribution.

Presupposing the distribution of the fundamental physical properties over the whole of space-time as primitive means that this distribution is entirely contingent. It is not only contingent that there is the distribution of fundamental physical properties as a whole that there is in fact, but each element in that distribution is also contingent. That is the point of denying necessary connections. Consequently, for each single token of a fundamental physical property at a space-time point, it is conceivable and metaphysically possible to hold that token (or its counterpart) fixed and to vary all the other tokens. Assuming that space-time and the distribution of fundamental physical properties in the universe originate in the socalled big bang, given the big bang, in what manner the distribution of fundamental physical properties in the universe develops is contingent. Given a possible world that is a duplicate of the big bang of the actual world, the development of the distribution of the fundamental physical properties in that possible world may be entirely different from the development of the distribution of the fundamental physical properties in the actual world. In short, the physical properties instantiated at any given space-time point or region do not impose any restrictions at all on the physical properties that can be instantiated at other space-time points or regions (Beebee 2006).

121 By way of consequence, the fact that there are regularities in the distribution of the physical properties in space-time - and what these regularities are - has to be accepted as primitive. Certain of these regularities are laws of nature. The most prominent proposal to distinguish the regularities that are laws within Humean metaphysics is the one of Ramsey-Lewis: the statements of laws of nature are all and only the theorems of the system that achieves the best balance between simplicity and strength in empirical content in providing a complete description of the world (Lewis 1973b, 72-75, and 1994, section 3). 
That view faces a number of objections, stemming notably from the concern that the criteria of simplicity and strength are subjective, being epistemic virtues, instead of objective, being anchored in the world. What is important for our purposes is that according to Humean metaphysics, there first is the distribution of fundamental physical properties over the whole of space-time, and then come the laws as supervening on that distribution. What the laws of nature are hence is fixed only at the end of the world.

The same goes for causation. Which property tokens stand in a relation of cause to effect supervenes on the distribution of the fundamental physical properties over the whole of spacetime. According to a Humean regularity view of causation, all there is to causation are certain patterns of spatio-temporarily contiguous co-instantiations of properties over the whole of space-time. Hence, whether or not two given property tokens stand in a relation of cause to effect depends on what else there is in the world, namely on whether or not tokens of the same types as the two given ones are regularly co-instantiated.

Nothing of substance changes if one switches to a counterfactual account of causation such as the one proposed by David Lewis (1973a) and (2004). Causation consists in certain counterfactual relations among property tokens. The statements describing these relations are made true by the distribution of the fundamental physical properties over the whole of spacetime in the actual world (Loewer 2007, 308-316). Lewis' theory of causation in terms of Humean supervenience does not commit one to accept his modal realism, that is, the view that other possible worlds exist, although finding out the truth-value of the counterfactual statements describing causal relations involves the comparison with other possible worlds. Whether or not a given counterfactual statement is true at the actual world depends on the laws holding at the actual world among other things. Hence, again, whether or not two given property tokens stand in a relation of cause to effect depends only on what else there is in the actual world, but it depends on all there is in the actual world, since the laws supervene on the distribution of the fundamental physical properties as a whole.

The fundamental physical properties are intrinsic and categorical. There are no powers or dispositions at space-time points over and above the intrinsic and categorical properties that occur at these points. Indeed, Humean metaphysics has 122 no reason to admit dispositions at all. The standard Humean and empiricist account proceeds in two steps:

- a semantic step that consists in translating statements that ascribe dispositions to objects into counterfactual conditional statements;

- an ontological step consisting in the claim that these statements are made true by the distribution of the fundamental, intrinsic and categorical physical properties over the whole of space-time (and the laws of nature - but the laws supervene on that distribution). Consequently, given the second step, there is no need to recognize dispositions over and above categorical properties.

The conditional analysis of disposition ascriptions has come under attack in the nineties (Martin 1994, Bird 1998). That attack triggered a new debate on the ontological status of dispositions. But there are persuasive replies to that attack available that restore the conditional analysis of disposition ascriptions, starting with Lewis himself (Lewis 1997 and then notably Gundersen 2002, Cross 2005, 323-325, Sparber 2006 and Choi 2008). In any case, the conditional analysis of disposition ascriptions on its own is not able to decide the issue of the ontology of dispositions (Malzkorn 2000). That issue depends on fundamental metaphysical considerations. 
Nothing in Humean metaphysics hinders that the world can be deterministic. A Hume world can be such that, given complete knowledge of its initial conditions - e.g., the physical conditions at the big bang - and the laws of nature, it is in principle possible to deduce the description of everything there is in the world. A Hume world thus is compatible with the letter of Laplacean determinism. However, the laws of nature merely have a descriptive function. What the laws are is fixed only at the end of the world, since their supervenience basis is the distribution of the fundamental physical properties over the whole space-time. The statements of laws of nature simply sum up at the end of the world what there is in the world.

One can therefore maintain that Humean metaphysics violates in any case the spirit of determinism, that is, the ideas that are associated with determinism: in a Hume world, the laws and the initial conditions do not determine the development of the distribution of physical properties in the sense that they are the ground for the existence of that development. Consequently, some Humeans hold that in a Hume world, there is no reason to raise concerns about whether or not determinism is compatible with free will: there is no such problem, since the laws depend on what there will be in the future and not the other way round (Beebee \& Mele 2002).

Humean metaphysics consequently faces the problem of induction in a metaphysical form: there is nothing in the past distribution of properties that could make true the prediction that the future distribution of properties will be like the past one. Lewis (1994, section 3) assumes that nature is kind to us, that is, that 123 there will be a few simple salient regularities that apply to the distribution of the physical properties throughout the whole universe; but there is nothing in the past distribution of properties that could make such a claim about the whole universe true. Of course, a Hume world can be such that the fundamental physical tokens in a limited region of space-time are de facto sufficient as a supervenience basis for the laws of nature in the following sense: the best system describing that limited region of space-time is identical or comes close to the best system describing the whole world, since the distribution of the fundamental physical properties is uniform throughout the whole world. But the point is that there is nothing in the limited region of space-time considered - or in any region of space-time that is a proper part of the whole of space-time - that can make true the belief that space-time as a whole is like the proper part considered. Note that this is a point about the metaphysical relation of truth-making and not about the epistemological problem of the justification of beliefs acquired by induction (that latter problem remains even if - as in the metaphysics of powers - the former, metaphysical problem does not arise).

According to Humean metaphysics, the world can be deterministic in the explained sense, but it can also be probabilistic. In a Hume world, the regular patterns can be such that not all $F$ s are followed by $G$ s (supervenience basis for deterministic laws), but that only a certain proportion of the $F \mathrm{~s}$ in the universe are followed by $G \mathrm{~s}$ (supervenience basis for probabilistic laws). If $F$ and $G$ are fundamental physical properties, these probabilities are irreducible and objective. The Humean account of probabilities is based on frequencies, but it is more sophisticated than a simple analysis in terms of relative frequencies, invoking the epistemic virtues of simplicity and strength that enter into the Humean best system account of laws of nature among others (Lewis 1994 and see Frigg \& Hoefer 2007 for an application to the quantum probabilities). However, for a Humean, the difference between a deterministic and a probabilistic world is not important as far as metaphysics is concerned, since every element in 
the distribution of the fundamental physical properties over the whole of space-time is contingent.

Consequently, the second law of thermodynamics (increase in entropy) simply describes a regularity pattern in the distribution of the fundamental physical properties in space-time. The same pattern can be described by statistical mechanics. If one takes for granted that there is a global increase in entropy, the description of the world by thermodynamics as well as by statistical mechanics presupposes that the state of the universe immediately after the big bang is a state of extremely low entropy. This presupposition is known as the past hypothesis. The extremely low entropy at the beginning of the universe is a contingent matter of fact. Nonetheless, on the Ramsey-Lewis view of laws of nature, it is possible to include the description of that fact among the theorems of the best system: admitting that 124 description as theorem amounts to a considerable gain in simplicity (Callender 2001, section 2.8). Furthermore, there is no intrinsic direction of time. The most widespread account within the framework of Humean metaphysics consists in saying that the direction of time supervenes on the distribution of fundamental physical properties which is such that there is an increase in entropy, and that increase in entropy accounts for the direction of time (see Loewer 2007).

Hence, to sum up, on the one hand, Humean metaphysics is parsimonious because it accepts only the distribution of the fundamental physical properties as primitive and it conceives these properties as being intrinsic and categorical; on the other hand, there is in Humean metaphysics no answer to the question why the distribution of fundamental physical properties in the universe developed as it did. Causation and laws supervene on that distribution; consequently, they cannot account for it. If one rejects the idea of there being necessary connections among the property tokens in the world, the consequence is that one has to accept the whole distribution of the fundamental physical properties as primitive. If one shrinks back from that consequence, one has to make a case for there being necessary connections in the world.

\subsection{Causal properties}

One possibility to conceive necessary connections is to admit not only particulars (property tokens), but also universals (property types) and regard the laws of nature as certain relations among universals (Armstrong 1983). Laws of nature are then conceived as governing the development of the distribution of the fundamental physical property tokens in the world. However, on that view, universals are simply added to the Humean account, and the objections against Humeanism can be reiterated on the level of the property types as universals. Furthermore, the ontological relationship between the universals and the particulars remains unclear. I shall therefore not pursue that view in this paper.

If one remains within the scope of an ontology of property tokens, leaving open whether or not there are universals over and above the property tokens, and nevertheless seeks to recognize metaphysically necessary connections among distinct entities, one has to conceive the particulars that there are in the world as being such that some particulars are the ground of the existence of other particulars - such that, given the former particulars, the latter cannot fail to be there. This is the case if and only if some particulars bring about the existence of other particulars. In other words, they have the power to produce other particulars. Hence, conceiving metaphysically necessary connections among distinct entities within an ontology of particulars commits us to admitting powers. The fundamental physical properties bestow 
powers on the objects that instantiate these properties or, simply, these 125 properties are powers. I shall use that latter expression for the sake of simplicity (without thereby taking a stance on the issue of the relationship between objects and properties in this paper). We thus get to a causal view of properties in contrast to the Humean view of properties being categorical. Since the powers in the sense just outlined are fundamental, they are irreducible. They thus are dispositions without a categorical basis - in other words, ungrounded dispositions.

There are two versions of an anti-Humean metaphysics of powers discussed in the current literature:

1) The one version considers each property to be categorical and dispositional in one. More precisely, to the extent that there is a distinction between the categorical and the dispositional, it is a distinction among predicates or descriptions instead of properties (Martin 1997, in particular sections 3 and 12; Mumford 1998, chapter 9; Heil 2003, chapter 11). Each property thus is a power and a quality at the same time.

2) The other version identifies properties with dispositions in the sense of powers (Shoemaker 1980, Bird 2007, as well as Hawthorne 2001 who calls this view "causal structuralism" and furthermore Ellis 2001, in particular chapters 1 and 3; Ellis, however, admits powers as well as categorical properties as two different kinds of properties existing in the world). Properties are powers, consisting in the disposition to produce certain effects.

The difference between these two versions is not as great as it might seem at first glance: the first version does not conceive the distinction between the categorical and the dispositional as an ontological one; it is not even admissible to talk in terms of categorical and dispositional aspects of properties, for such aspects would in turn be properties. Dispositions or powers are not properties of properties, but properties are dispositions or powers. Thus, John Heil describes the last view of Charlie Martin as conceiving properties as "powerful qualities" (Heil 2009, 178). The second version does not conceive powers as pure potentialities, but as real, actual properties. They thus are certain qualities that necessarily manifest themselves in the production of certain effects.

The important point is that powers are not additional properties. Qua being a certain way that is, qua being qualitative -, property tokens are the powers to produce further property tokens. To put the matter in terms of object talk, qua being a certain way, that is, by having certain qualities, objects have the power to produce other objects, or other properties in objects. Take charge for example: insofar as charge is a qualitative property, distinct from e.g. mass, it is the power to build up an electromagnetic field, resulting in the attraction of opposite-charged and the repulsion of like-charged objects. The Humean and the antiHumean agree about the properties that there are in the world. They disagree about the ontology of properties - whether the property tokens are such that they simply succeed 126 one another or whether they are such that each property token brings about other property tokens.

The metaphysics of powers accepts as primitive that properties are powers - more precisely, accepts as primitive the fact that qua being a certain way, being a certain quality, each property token is the power to produce certain other property tokens. The laws of nature supervene on the properties. If it is a law that all $F \mathrm{~s}$ are followed by $G \mathrm{~s}$, this is so because the $F$ s are the power to produce $G$ s. Consequently, instead of the contingent regularity patterns in 
Humean metaphysics, according to the metaphysics of powers, the laws of nature are metaphysically necessary: if something is a token of the property $F$, it is the power to produce $G$ s. Hence, in any world in which there are $F$ s, the law that $F$ s produce $G$ s holds.

The same goes for causation. Causal relations are not a simple pattern of regular contiguous co-instantiations of properties of the same types, but one property token literally produces or brings about other property tokens and thus is the ground of the existence of those other property tokens. However, in recent literature, doubts are expressed as to whether in case one conceives the fundamental properties as dispositions and thus in a causal manner, one inevitably is committed to recognizing necessary connections in the world, thereby contradicting Humean metaphysics (Handfield 2008, Anjum \& Mumford 2009).

Nonetheless, there is a clear contrast between the Humean metaphysics of categorical properties and a metaphysics that conceives properties in a dispositional and thus a causal manner, namely as powers. According to Humean metaphysics, properties of the same type can stand in very different causal relations in different possible worlds. For instance, Humean metaphysics admits a possible world in which the property type that plays the charge role in the actual world plays the mass role, and vice versa. By contrast, according to the metaphysics of powers, the qualitative character of a property type determines the causal role that the property type in question plays and hence determines the causal relations in which the tokens of the property type in question stand. That is why the metaphysics of powers is a causal theory of properties, whereas Humean metaphysics is not a causal theory of properties. Since, following the metaphysics of powers, it is the nature of the properties to produce certain effects, the connection between cause and effect is a necessary one: the property tokens cannot but produce the effects in question.

Determinism has a much more substantial meaning in the metaphysics of powers than in Humean metaphysics. The metaphysics of powers suggests the view that if there is an initial state of the world, the big bang, the properties instantiated at the big bang are powers that bring about the subsequent development of the universe. In other words, the initial state of the world necessitates all there is in the world. Consequently, any possible world that is an exact duplicate of the initial state of 127 the actual world is an exact duplicate of the actual world as a whole. Determinism, thus conceived, clearly raises the problem of whether or not it is compatible with free will. Note that this conception of determinism does not invoke the notion of laws of nature. The powers as such account for the world being deterministic. The laws are derived from the powers. Nonetheless, of course, it is true on this account that given the laws and the initial conditions at the origin of the universe it is in principle possible to predict everything that there is in the universe.

However, the metaphysics of powers is not committed to determinism. If it were, that would be a weighty objection against it, since there are reasons to believe that the actual world is not deterministic. There are two options within the metaphysics of powers to introduce probabilities: the one possibility is to take the property $F$ to be the power to produce tokens of the property $G$ among others, but to say that it is a matter of pure chance when an $F$ exercises that power. For instance, one may think of two radioactive atoms of the same type in the same environment, the one decays within a given time, the other one does not decay within that time. On this account, however, probabilistic laws are nothing more than Humean regularities: at the end of the world, they simply describe what percentage of the $F$ s has produced a $G$. 
The other, much more widespread option is to make the notion of a power more precise by employing the concept of propensities (Popper 1990). On a widespread account of propensities, the power of $F$ s to produce $G$ s is conceived as a certain tendency intrinsic to each $F$ to bring about a $G$, and that tendency has a certain strength. If, for instance, the strength of the power of $F \mathrm{~s}$ to produce $G$ s is 0.6 , then that is the reason why $60 \%$ of the $F \mathrm{~s}$ in the universe bring about a $G$. Consequently, probabilistic laws, like deterministic laws, are not Humean regularities. They supervene on the powers, and they are metaphysically necessary. The main advantage of the account in terms of propensities is to provide for objective single case probabilities. Frequencies supervene on the propensities. They are of course the guide to gain cognitive access to the propensities. On that basis, the propensity theory of probabilities can take the Principal Principle into account that adapts our subjective degrees of beliefs to objective chance: in finding out what the correct probability distribution is in a given case, we learn which subjective degrees of belief are rational to adopt.

The metaphysics of causation in terms of powers is linked with the view of an intrinsic direction of time. The connection between a token of $F$ and a token of $G$ is a causal one if and only if the $F$ produces the $G$. One can argue that causation thus is the basis for the direction of time: the $G$, being produced by the $F$, lies in the future of the $F$. Causal processes are the first and foremost example of irreversible processes: the relationship between a cause and its effect cannot be reversed. There hence is a direction of time because there are causal processes.

128 As regards the initial state of the universe, it is simply a contingent matter of fact that, according to the past hypothesis, this is a state of extremely low entropy. Whereas the Ramsey-Lewis view of laws can promote the description of that state to a theorem of the best system, the metaphysics of powers simply has to acknowledge the low entropy of the initial state of the universe to be a contingent fact. Nonetheless, any metaphysical position has to accept something as primitive. In contrast to Humean metaphysics, the metaphysics of powers does not have to regard the whole distribution of fundamental physical properties in spacetime as primitive. Powers establish a necessary connection between at least some of these properties. In the ideal case of a completely deterministic world, one only has to accept the initial state of the universe as primitive, and the powers instantiated at the initial state of the universe are the ground of the existence of the development of the distribution of the fundamental physical properties throughout the whole of space-time.

To sum up, the issue of Humean metaphysics vs. a metaphysics of powers concerns the categorical vs. the causal view of properties. If the fundamental physical properties are categorical, then the whole distribution of them has to be accepted as primitive, because there are no necessary connections among them. If, on the contrary, the fundamental physical properties are powers, then a proper part of the property tokens instantiated in the world (in the ideal case, those ones at the big bang) is the ground of the existence of the rest of the fundamental property tokens in the world, there thus being necessary connections between property tokens in the world.

\subsection{The master argument against Humeanism and the ontology of science}

There is a central objection that can be seen as the master argument against Humeanism. According to Humean metaphysics, the causal relations and the laws of nature vary from possible world to possible world, depending on what else there is in a world in which properties of the type $F$ are instantiated. Thus, what $F$ is neither depends on the effects that 
the tokens of $F$ have nor on the laws in which $F$ figures in different possible worlds. The objection now is this one: we gain knowledge about the world via the causal relations in which what there is in the world stands. A difference that does not give rise to a causal difference is a difference of which we cannot gain knowledge. Hence, we can specify what there is in the world only down to causal equivalence. If the properties themselves are not causal ones, but categorical, intrinsic ones, possessing an essence beyond that specification, it follows that their essence is a primitive suchness (quiddity) that is beyond the grasp of our knowledge. The Humean thus is committed to the 129 positions known as quidditism and as humility (Lewis 2009 endorses both these commitments).

The commitment to quidditism and humility as its consequence are rather uncomfortable: there are worlds that are different because they differ in the distribution of the intrinsic properties that are instantiated in them, although there is no difference in causal and nomological relations and thus no discernible difference between them. A quidditistic difference between worlds is a qualitative difference (by contrast to a haecceistic difference, concerning the question which individuals there are in a given world) that implies that worlds have to be counted as different although they are indiscernible (Black 2000). A gap between metaphysics - postulating primitive qualities (a primitive suchness) - and epistemology thus arises. These commitments are at odds with a metaphysics that seeks to be close to empirical science - postulating that there are primitive qualities in the world that lead to having to recognize possible worlds as qualitatively different although they are indiscernable. These consequences therefore constitute a strong argument in favour of the causal theory of properties in general (Shoemaker 1980 and 2007, appendix).

Hence, although Humean metaphysics seems to be parsimonious at first glance, it is not that parsimonious after all, postulating that properties have an essence beyond the causal relations into which they enter, that essence consisting in a primitive suchness which is beyond the grasp of our knowledge. Deleting these commitments leads to the causal theory of properties, namely to the view that there is nothing more to the properties than the power to bring about certain effects, and that view then commits us to countenance necessary connections, as explained above. However, seen from the perspective of avoiding the commitments to quidditism and humility, the commitment to necessary connections is not at all mysterious or ontologically inflationary.

If we take properties to be causal powers and if the main argument for adopting that view is to abandon the commitments to quidditism and humility, then the fundamental properties cannot be conceived as needing outside manifestation conditions for exercising the powers that they are. Otherwise, there could be fundamental properties of two different types $F$ and $F^{*}$ present in the world without that difference showing up anywhere because the appropriate manifestation conditions always lack. It is unproblematic to conceive the fundamental properties as not needing outside manifestation conditions in order to exercise the powers that they are, since these powers are not pure potencies, but real, actual properties. The appropriate model are not macroscopic dispositions such as the disposition of water to dissolve sugar, but rather the dispositions of radioactive atoms for spontaneous decay or of particles with charge to build up electromagnetic fields.

130 However, it seems questionable whether the causal theory of properties is compatible with physics. Since Russell's 1912 famous paper denouncing the notion of causation as production, a lot of Humeans claim that the notion of powers does not fit into our 
fundamental physical theories. All that these theories state are certain regularities in the distribution of physical properties. There is thus not more to causation than Humean regularities (cf. notably the papers in Price \& Corry 2007).

Nonetheless, the situation is not as clear as Russell and his contemporary followers represent it. Characterizations of the fundamental physical properties in dispositional terms are widespread (Mumford 2006, 475-477). As regards the fundamental physical, intrinsic properties, one can conceive charge, for instance, as the power to build up an electromagnetic field, mass as the power to resist acceleration, etc. It is true that the causal conception of these properties is not mandatory. One can also characterize these properties in terms of certain mathematical structures, namely as being invariant under certain symmetry relations that constitute a mathematical group (Psillos 2006, 151-154). However, it is trivial that any physical property can be represented by a mathematical structure. That representation does not imply that the property itself is a mathematical structure, on pain of blurring the distinction between the mathematical and the physical. In short, that manner of representation leaves open what the nature of the properties thus represented is. As far as fundamental physical, intrinsic properties such as charge or mass are concerned, instead of taking their essence to be a primitive suchness (quiddity), it is an attractive and viable option in the philosophy of physics to consider them as causal powers.

In the recent literature in the philosophy of physics, stress is laid not only on mathematical structures representing physical properties, but it is claimed with sound arguments from the current fundamental theories (quantum theory and general relativity theory) that some central fundamental physical properties are themselves physical structures rather than being intrinsic properties. A physical structure can be conceived as network of concrete qualitative, physical relations among objects that do not possess any intrinsic identity and thus no intrinsic properties on which these relations could supervene. The resulting position is known as ontic structural realism (Ladyman 1998, French \& Ladyman 2003, Esfeld 2004). However, the founders of ontic structural realism tend to conceive these physical structures in an antiHumean way, namely as including a primitive modality (French 2006, Ladyman \& Ross 2007, chapters 2 to 5). One way of elaborating on that view of a primitive modality is to apply the causal theory of properties to the fundamental physical structures as conceived by ontic structural realism.

131 As far as quantum theory is concerned, the argument in support of ontic structural realism is that the state-dependent properties of quantum objects are subject to entanglement such that, in brief, there are only relations of entanglement among these objects and no statedependent properties that each of these objects possesses on its own. State-dependent properties are position, momentum, spin angular momentum in each of the three spatial directions, etc. If one recognizes entangled states and if one maintains that there also are classical physical properties, at least when it comes to macroscopic objects, one has to conceive a transition from entangled states to so-called product states, which amount to statedependent properties of quantum objects with definite numerical values. The most elaborate physical proposal for such a transition is the one going back to Ghirardi, Rimini and Weber (1986) (GRW). The interpretation of quantum theory by GRW lends itself to an account in terms of dispositions: the entangled states are the power - more precisely, the propensity - to produce product states, that is, classical physical properties with definite numerical values localized in classical space-time (Dorato 2006, Suárez 2007). Conceiving the entangled states 
in that manner provides for a clear answer to the question what the properties of quantum objects are if there are no properties with definite numerical values, namely propensities for spontaneous localizations. Furthermore, it yields objective single case probabilities and it makes clear how a structure can be a power and how it can exercise the power that it is without needing external manifestation or triggering conditions: the disposition (propensity) in question is one for spontaneous localization. Since entangled states are nonseparable, it is evident that this disposition (propensity) has to be inherent in the entangled state as a whole, viz. that the entangled state as a whole $i s$ the disposition or power for spontaneous localization.

As far as general relativity theory is concerned, there are sound arguments, notably the hole argument, for conceiving the metrical field as being part and parcel of space-time and thus as regarding the properties of space-time points as consisting in the metrical relations among them (Esfeld \& Lam 2008). If the metrical field belongs to space-time, space-time is no passive background arena, but itself a dynamical entity, containing energy, namely the gravitational energy, and gravitation is a physical interaction on a par with the other physical interactions, such as electromagnetism. This situation makes it possible not only to apply ontic structural realism to space-time as well, but also to conceive the metrical relations themselves in a causal manner, namely as the power to produce the observed gravitational phenomena among others (Bartels 1996, 37-38, and Bartels 2009 as well as Bird 2009, section 2.3). One can thus avoid an unsatisfactory dualism of on the one hand causal properties or structures and on the other hand purely categorical, structural properties.

132 Again, it is not mandatory to conceive the fundamental physical structures in a causal manner as powers. But there are mainly three arguments for doing so: (1) Applying the causal theory of properties to the fundamental physical structures provides for a clear answer to the question what distinguishes physical from mathematical structures: physical structures are causal, whereas mathematical structures are not. (2) This conception yields a unified ontology that includes properties such as charge and mass, that is, physical properties for which there is no argument available that is comparable to the arguments from state-dependent properties in entangled states and metrical properties and that shows that these properties themselves are physical - structures. (3) This conception establishes a firm link between the fundamental physical structures, which are theoretical entities, and the observable phenomena, making clear how we can have cognitive access to these structures and thus opening up the way for vindicating a realist attitude towards them (Esfeld 2009).

The last argument calls into question whether Humean metaphysics really is entitled to realism with respect to the fundamental physical properties. Whereas Lewis himself considers these properties to be intrinsic, Humean metaphysics can be adapted to current physics by shifting the focus from intrinsic properties to relations or structures (such as the structures of quantum entanglement) (Sparber 2009). The point at issue, however, is whether Humean metaphysics can justify a realist stance with respect to the theoretical entities in which current physics trades: since, according to the Humean, the nature of these entities does not consist in bringing about effects that are observable, what the underlying structures are seems to be underdetermined by the observable effects. Consequently, the result risks to be an agnosticism rather than a scientific realism with respect to the fundamental physical structures (cf. the empiricist structural realism of van Fraassen 2006). Such a realism, however, is crucial for Humean metaphysics: Lewis maintains in his thesis of Humean supervenience 
quoted above that all there is to the world is the distribution of the fundamental physical, categorical properties in space-time. Everything that there is in the world is a feature of that distribution. Thus, everything is traced back to the theoretical entities of fundamental physics.

Nonetheless, there is more to science than physics. There also are the non-physical special sciences, such as notably biology and psychology. These sciences trade in functional properties. Those properties consist in producing certain effects given standard conditions. Thus, for instance, a gene consists in producing certain specific phenotypical effects given standard conditions; a functional, mental property consists in producing certain further mental properties as well as a certain behaviour given standard conditions, etc. Functional properties, however, cannot be conceived as categorical properties, for what they are consists in the effects that they cause. What these properties are can thus not be separated from the 133 causal and the nomological relations in which they stand. Humean metaphysics can acknowledge functional descriptions: the distribution of the categorical fundamental physical properties (or structures) over the whole universe can be such that it makes true certain functional descriptions. But Humean metaphysics cannot admit functional properties: in a Hume world, there cannot be properties whose identity consists in causing certain effects, for all there is in a Hume world is the distribution of categorical properties. Hence, Humean metaphysics may be in the position to provide truthmakers for the functional descriptions and theories of the special sciences, but it is committed to an eliminativist attitude with respect to the functional properties in which these sciences trade (Esfeld 2007).

By contrast, the metaphysics of powers has no problem in accommodating the functional properties in which the special sciences trade. One may go as far as maintaining that the causal theory of properties (Shoemaker 1980) is tailor-made for functional properties, since what a property is consists in the effects that the property tokens in question produce. However, as mentioned above, there are also good arguments for extending the causal theory of properties to the physical properties, including the fundamental physical properties and structures. The metaphysics of powers thus is an ontology that pays tribute to the commitments of both physics and the special sciences. As far as that ontology is concerned, nothing hinders that the properties in which the special sciences trade are at least tokenidentical with certain physical properties. But that identity is in any case conservative instead of an eliminativism with respect to the special sciences' properties, since what the properties are consists in the production of certain effects, and some of these effects are those ones on which the special sciences focus.

In conclusion, summing up this section, there are two main arguments for preferring the metaphysics of powers to Humean metaphysics: (1) The metaphysics of powers avoids the commitments to quidditism and humility. (2) It provides for a complete and coherent ontology that includes the ontological commitments of physics as well as of the special sciences.

\section{References}

Anjum, Rani Lill \& Mumford, Stephen (2009): "Dispositional modality”. Forthcoming in: C. F. Gethmann (ed.): Lebenswelt und Wissenschaft. XXI. Deutscher Kongress für Philosophie. Kolloquien. Hamburg: Meiner.

Armstrong, David M. (1983): What is a law of nature? Cambridge: Cambridge University Press.

Bartels, Andreas (1996): "Modern essentialism and the problem of individuation of spacetime points". Erkenntnis 45, pp. 25-43. 
Bartels, Andreas (2009): "Dispositionen in Raumzeit-Theorien”. Forthcoming in: C. F. Gethmann (ed.): Lebenswelt und Wissenschaft. XXI. Deutscher Kongress für Philosophie. Kolloquien. Hamburg: Meiner.

Beebee, Helen (2006): "Does anything hold the world together?". Synthese 149, pp. 509-533.

Beebee, Helen \& Mele, Alfred (2002): "Humean compatibilism”. Mind 111, pp. 201-223.

Bird, Alexander (1998): "Dispositions and antidotes". Philosophical Quarterly 48, pp. 227-234.

Bird, Alexander (2007): Nature's metaphysics. Laws and properties. Oxford: Oxford University Press.

Bird, Alexander (2009): "Structural properties revisited". In: T. Handfield (ed.): Dispositions and causes. Oxford: Oxford University Press. Pp. 215-241.

Black, Robert (2000): “Against quidditism”. Australasian Journal of Philosophy 78, pp. 87-104.

Callender, Craig (2001): “Thermodynamic asymmetry in time”. In: E. N. Zalta (ed.): Stanford Encyclopedia of Philosophy. http://plato.stanford.edu/archives/win2001/entries/time-thermo.

Choi, Sungho (2008): "Dispositional properties and counterfactual conditionals". Mind 117, pp. 795-841.

Cross, Troy (2005): “What is a disposition?" Synthese 144, pp. 321-341.

Dorato, Mauro (2006): "Properties and dispositions: some metaphysical remarks on quantum ontology". In: A. Bassi, D. Dür, T. Weber \& N. Zanghi (eds.): Quantum mechanics: Are there quantum jumps? On the present state of quantum mechanics (American Institute of Physics Conference Proceedings 844). New York: American Institute of Physics. Pp. 139-157.

Ellis, Brian (2001): Scientific essentialism. Cambridge: Cambridge University Press.

Esfeld, Michael (2004): "Quantum entanglement and a metaphysics of relations". Studies in History and Philosophy of Modern Physics 35B, pp. 601-617.

Esfeld, Michael (2007): "Mental causation and the metaphysics of causation". Erkenntnis 67, pp. 207-220.

Esfeld, Michael (2009): "The modal nature of structures in moderate structural realism". International Studies in the Philosophy of Science 23, pp. 179-194.

Esfeld, Michael \& Lam, Vincent (2008): "Moderate structural realism about space-time”. Synthese 160, pp. 2746.

French, Steven (2006): "Structure as a weapon of the realist". Proceedings of the Aristotelian Society 106, pp. 167-185.

French, Steven \& Ladyman, James (2003): "Remodelling structural realism: quantum physics and the metaphysics of structure". Synthese 136, pp. 31-56.

Frigg, Roman \& Hoefer, Carl (2007): "Probability in GRW theory". Studies in History and Philosophy of Modern Physics 38B, pp. 371-389.

Ghirardi, Giancarlo, Rimini, Alberto \& Weber, Tullio (1986): "Unified dynamics for microscopic and macroscopic systems". Physical Review D 34, pp. 470-491.

Gundersen, Lars (2002): "In defense of the conditional-account of dispositions". Synthese 130, pp. 389-411.

Handfield, Toby (2008): "Humean dispositionalism”. Australasian Journal of Philosophy 86, pp. 113-126.

Hawthorne, John (2001): "Causal structuralism”. Philosophical Perspectives 15, pp. 361-378.

Heil, John (2003): From an ontological point of view. Oxford: Oxford University Press.

Heil, John (2009): “Obituary. C. B. Martin”. Australasian Journal of Philosophy 87, pp. 177-179.

Ladyman, James (1998): "What is structural realism?" Studies in History and Philosophy of Modern Science 29, pp. $409-424$.

Ladyman, James \& Ross, Don (2007): Every thing must go: metaphysics naturalised. Forthcoming Oxford: Oxford University Press 2007.

Lewis, David (1973a): “Causation”. Journal of Philosophy 70, pp. 556-567. Reprinted in D. Lewis (1986): Philosophical papers. Volume 2. Oxford: Oxford University Press. Pp. 159-172.

Lewis, David (1973b): Counterfactuals. Oxford: Blackwell.

Lewis, David (1986): Philosophical papers. Volume 2. Oxford: Oxford University Press.

Lewis, David (1994): "Humean supervenience debugged". Mind 103, pp. 473-490. Reprinted in D. Lewis (1999): Papers in metaphysics and epistemology. Cambridge: Cambridge University Press. Pp. 224-247. 
Lewis, David (1997): "Finkish dispositions". Philosophical Quarterly 47, pp. 145-158. Reprinted in D. Lewis (1999): Papers in metaphysics and epistemology. Cambridge: Cambridge University Press. Pp. 133-151.

Lewis, David (2004): "Causation as influence”. In: J. Collins, N. Hall \& L. A. Paul (eds.): Causation and counterfactuals. Cambridge (Massachusetts): MIT Press. Pp. 75-106.

Lewis, David (2009): “Ramseyan humility”. In: D. Braddon-Mitchell \& R. Nola (eds.): Conceptual analysis and philosophical naturalism. Cambridge (Massachusetts): MIT Press. Pp. 203-222.

Loewer, Barry (2007): "Counterfactuals and the second law". In: H. Price \& R. Corry (eds.) (2007): Causation, physics, and the constitution of reality. Russell's republic revisited. Oxford: Oxford University Press. Pp. 293-326.

Malzkorn, Wolfgang (2000): "Realism, functionalism, and the conditional analysis of dispositions". Philosophical Quarterly 50, pp. 452-469.

Martin, C. B. (1994): "Dispositions and conditionals”. Philosophical Quarterly 44, pp. 1-8.

Martin, C. B. (1997): "On the need for properties: the road to Pythagoreanism and back". Synthese 112, pp. 193231.

Mumford, Stephen (1998): Dispositions. Oxford: Oxford University Press.

Mumford, Stephen (2006): “The ungrounded argument”. Synthese 149, pp. 471-489.

Popper, Karl R. (1990): A world of propensities. Bristol: Thoemmes.

Price, Huw \& Corry, Richard (eds.): Causation, physics, and the constitution of reality. Russell's republic revisited. Oxford: Oxford University Press.

Psillos, Stathis (2006): “What do powers do when they are not manifested?". Philosophy and Phenomenological Research 72, pp. 137-156.

Russell, Bertrand (1912): "On the notion of cause”. Proceedings of the Aristotelian Society 13, pp. 1-26.

Shoemaker, Sydney (1980): "Causality and properties". In: P. van Inwagen (ed.): Time and cause. Dordrecht: Reidel. Pp. 109-135. Reprinted in S. Shoemaker (1984): Identity, cause, and mind. Philosophical essays. Cambridge: Cambridge University Press. Pp. 206-233.

Shoemaker, Sydney (2007): Physical realization. Oxford: Oxford University Press.

Sparber, Georg (2006): "Powerful causation”. In: M. Esfeld (ed.): John Heil. Symposium on his ontological point of view. Frankfurt (Main): Ontos. Pp. 123-137.

Sparber, Georg (2009): Unorthodox Humeanism. Frankfurt (Main): Ontos-Verlag.

Suárez, Mauricio (2007): "Quantum propensities". Studies in History and Philosophy of Modern Physics 38B, pp. 418-438.

van Fraassen, Bas C. (2006): "Structure: its shadow and substance". British Journal for the Philosophy of Science 57, pp. 275-307. 